\title{
Pericardial window used in the diagnosis of cardiac injury ${ }^{1}$
}

\author{
Janela pericárdica no diagnóstico de lesão cardíaca
}

\author{
Gustavo Pereira Fraga ${ }^{\text {, Juliana Pinho Espínola }}{ }^{\text {II }}$, Mario Mantovani ${ }^{\text {II }}$ \\ ${ }^{I}$ PhD, Assistant Professor, Division of Trauma Surgery, FCM - UNICAMP. Post Doctoral Fellow at University of California, San Diego \\ (UCSD) - scholarship from FAPESP. \\ II Graduate Student of FCM - UNICAMP and Scientific Initiation Student - FAPESP. \\ III PhD, Chairman and Head of Division of Trauma Surgery, FCM - UNICAMP.
}

\begin{abstract}
Purpose: The purpose of the present study is to analyze the results of subxiphoid pericardial window (SPW) and transdiaphragmatic pericardial window (TDP) procedures comparing the two techniques. Methods: During the period of January, 1994 to December, 2004, at UNICAMP, 245 patients underwent a pericardial window (PW) procedure to evaluate the possibility of cardiac injury. We reviewed the medical records of those patients in order to compare both procedures. Results: Two hundred and seven patients $(84.5 \%)$ underwent the SPW procedure, and $38(15.5 \%)$ underwent the TDP procedure. Of the patients who underwent a SPW procedure, $151(72.9 \%)$ had gunshots injuries, and $56(27.1 \%)$ had stab wounds. In the group of patients submitted to TDP procedure, the wound was caused by gunshot in $26(68.4 \%)$. The SPW method has shown a sensitivity of $97.5 \%$, specificity of $95.8 \%$, and an accuracy of $96.1 \%$. The TDP method demonstrated a sensitivity of $100 \%$, specificity of $97 \%$ and a $97.4 \%$ of accuracy rate. This review showed $8(3.3 \%)$ false positive results. There was a single case $(2.6 \%)$ of complications directly associated to the TDP, and this patient developed pericarditis. Conclusions: Both techniques presented an equally great result, with high sensitivity and specificity. Both surgical techniques must be carefully done to avoid false positive results.
\end{abstract}

Key words: Trauma. Penetrating wounds. Thoracic injuries. Heart. Pericardial window techniques.

\section{RESUMO}

Objetivo: Analisar os resultados da janela pericárdica subxifóidea (JPSX) e da janela pericárdica transdiafragmática (JPTD), comparando as duas técnicas. Métodos: Durante o período entre Janeiro de 1994 a Dezembro de 2004,245 pacientes foram submetidos à janela pericárdica (JP) na Unicamp, a fim de avaliar a presença de lesão cardíaca. Foram revisadas as informações destes pacientes a fim de comparar as técnicas de JP. Resultados: Duzentos e sete (84,5\%) pacientes foram submetidos à JPSX, e $38(15,5 \%)$ à JPTD. Dos pacientes que realizaram a JPSX, 151 (72,9\%) foram vítimas de lesões provocadas por projétil de arma de fogo (FPAF), e 56 (27,1\%) por arma branca (FAB). Em relação aos pacientes submetidos à JPTD, o ferimento foi causado por FPAF em $26(68,4 \%)$. O método JPSX teve uma sensibilidade de $97,5 \%$, especificidade de 95,8\%, e uma acurácia de 96,1\%. A JPTD resultou numa sensibilidade de 100\%, especificidade de $97 \%$ e 97,4\% de acurácia. Em 8 pacientes (3,3\%) o resultado foi falso-positivo. Houve um único caso $(2,6 \%)$ de complicação diretamente relacionada à JPTD. Conclusões: Ambas as técnicas apresentaram um bom resultado, com alta sensibilidade e especificidade. Entretanto, estes procedimentos cirúrgicos devem ser efetuados com cuidado, a fim de evitar resultados falso-positivos.

Descritores: Trauma. Ferimentos penetrantes. Lesões torácicas. Coração. Técnicas de janela pericárdica. 


\section{Introduction}

The cardiac injury is known as a common cause of death in trauma. Most patients with penetrating cardiac wounds do not reach the hospital alive, and many others arrive at the hospital in extremis ${ }^{1-3}$. Patients presenting acute pericardial tamponade or shock, and not responding to crystalloids infusion, usually do not present problems on diagnostic and are immediately operated.

Rapid cardiac injury diagnosis is necessary since $20 \%$ to $40 \%$ of patients who reach the hospital have no obvious signs or symptoms of cardiac injury, which can be temporary and have serious hemodinamic consequences like tamponading or bleeding ${ }^{4-8}$. As these patients may suddenly develop into a worse situation and bleed to death, ruling out a cardiac wound should be done as soon as possible. For such patients with stable signs, diagnostic methods range from noninvasive echocardiography $(\mathrm{ECHO})^{9-13}$ to invasive pericardial window $(\mathrm{PW})^{14-17}$ or thoracoscopy ${ }^{18,19}$.

Many patients admitted at our emergency department have multiple wounds therefore penetrating abdominal injuries need to be soon ruled out or treated. In these cases, we indicate an invasive procedure.

Many authors have presented their own experience using PW in the diagnosis of cardiac injury in stable patients $^{3-6,14,16}$. Most of the studies about this method consider it the gold standard as this procedure quickly identifies or excludes cardiac injuries and can be performed with minimal morbidity, even when there is contamination from the gastrointestinal tract.
The PW procedure is performed using two different techniques, a subxiphoid pericardial window $(\mathrm{SPW})^{15}$, or a transdiaphragmatic pericardial window (TDP) ${ }^{16}$.

The objective of the present study is to check the results of SPW and TDP procedures in patients attended by Trauma Surgery Division, by analyzing and comparing these two techniques.

\section{Methods}

From January 1994 to December 2004, at the Trauma Surgery Division of the State University of Campinas (UNICAMP), 2147 victims of accidents or violence were submitted to surgery. Out of those patients, 245 underwent a PW diagnostic procedure to evaluate the possibility of cardiac injury, after a penetrating trauma in the SauerMurdock area.

The sequence of diagnostic and therapeutic procedures adopted was in agreement with standards established by ATLS $^{\circledR 20}$. Patients who had closed cardiac injuries were excluded from this study.

The evaluation of hemodynamic stable patients with penetrating wound in heart proximity could be performed with noninvasive methods, such as focused assessment with sonography in trauma (FAST) or ECHO ${ }^{13}$. However, these methods have not been frequently used in our patients because there is no FAST equipment available in the emergency room at our hospital, and the ECHO must be performed by experts, which may delay the diagnosis. The videothoracoscopy is another diagnostic method of cardiac injury that has been used in thoracoabdominal trauma; however, the equipment is not often available (Figure 1).

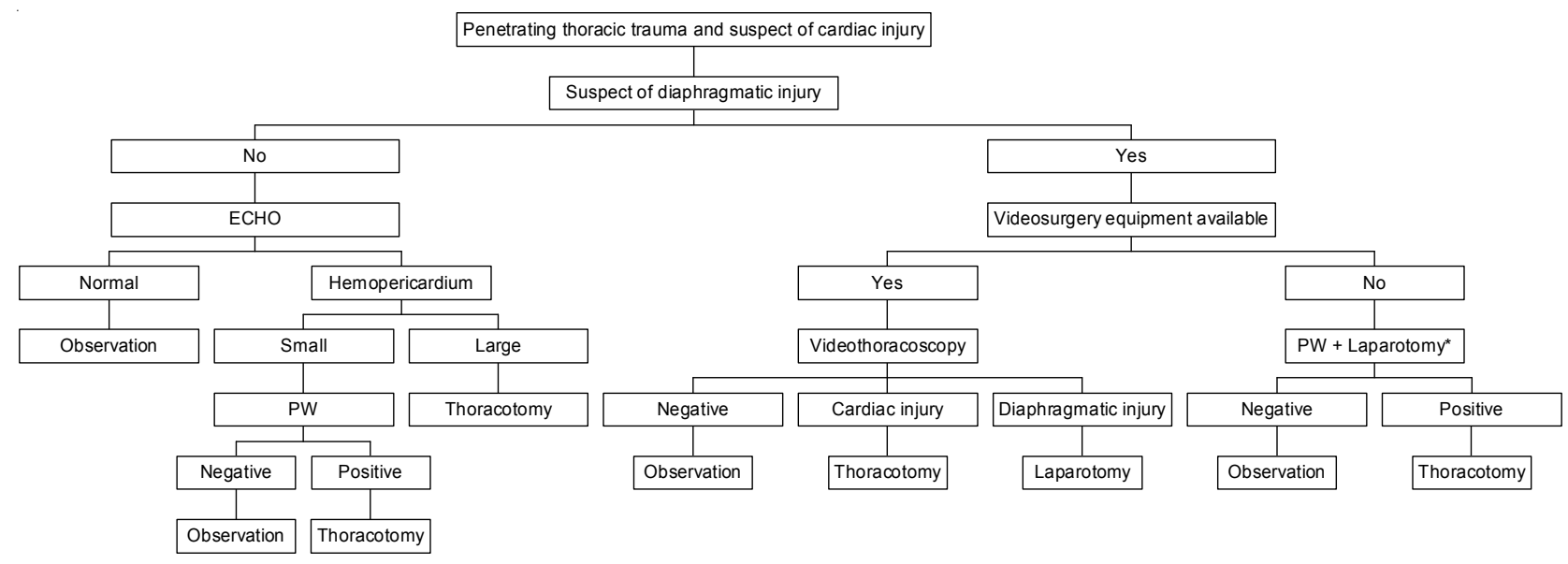

* Usually, we perform the PW first, and than the laparotomy. If there is a high suspect of abdominal injury, with severe bleeding, the laparotomy procedure is a priority.

FIGURE 1 - Sequence of diagnostic investigation methods in hemodynamic stable patients with suspect of cardiac injury. 
Medical records of these patients were reviewed in order to compare the SPW and TDP procedure results, analyzing mechanism of trauma, clinical findings, associated injuries, trauma score (ISS) ${ }^{21}$ and complications. There was no protocol guiding the study and the choice of each technique was according to the wound's site and the surgeons preferences.

The SPW technique is done in the operating room, with the patient in the recumbent position, with thorax elevation of $30^{\circ}$ and under general anesthesia. After the appropriate aseptic procedures a 5 to $8 \mathrm{~cm}$ vertical incision from the distal end of the body of the sternum, is made. The xiphoid process is grasped with a clamp and elevated so that the sternal attachment of the diaphragm can be detached and retracted inferiorly. The anterior diaphragm is dissected; the pericardium is visualized, palpated, and grasped between Allis clamps. Excellent hemostasia is mandatory in order to evaluate the quality of the pericardial effluent. A small vertical incision of 4 to $5 \mathrm{~mm}$ is then made in the pericardium, allowing the drainage of a few milliliters of clear fluid under normal circumstances, which is considered a negative SPW result. The incision is then closed without drains, by plans, with retarded absorption string, and skin is then closed with thin nylon. However, if any blood or clot is identified in the pericardial space, the result is considered positive, and either the incision can be converted to a median sternotomy, or a left-sided anterolateral thoracothomy is performed to repair the cardiac injury, according to the classification proposed by the American Association of Surgery of Trauma (AAST) $)^{5,22}$.

Over the last few years, when PW procedure presents unclear results, the pericardium is irrigated with warm saline and patients who have persistent bloody fluid undergo cardiac exploration.

In patients with combined thoracoabdominal trauma, and who are submitted to exploratory laparotomy, the TDP can be performed instead of the SPW ${ }^{16,17}$. The preoperative preparation is similar to the one used on the SPW procedure. Due to these injury characteristics, the surgeon needs a large thoracoabdominal exposure that extends from the body of the sternum to the navel scar or the pubis symphysis. The diaphragm is held by Allis clamp on each side of the tendinous portion and softly retracted inferiorly to dislocate the diaphragm and the pericardial sac from the apex of the heart. A 2 to $3 \mathrm{~cm}$ vertical incision is made in the midline of the tendinous portion of the diaphragm. The exposure of a tense and protuberant pericardic sac may prove the positive diagnostic. The incision of the pericardial sac usually results in the identification of free fluid, blood or clot. The absence of blood or clot is then interpreted as a negative TDP, and the incision of the pericadiotomy is closed. A positive TDP requires a median sternotomy or a thoracotomy.

This study was approved by the institutional Ethical Committee, and informed consent was not required. Data were compared by chi square analysis; $p$ values less than 0.05 were considered significant.

\section{Results}

Among the 245 patients that were submitted to PW procedure, two hundred and twenty seven (92.6\%) were men, and $18(7.4 \%)$ were women, with an age range of 13 to 73 years and an average age of 28.3 years. Of these patients, $207(84.5 \%)$ were submitted to SPW procedure, and 38 $(15.5 \%)$ to TDP procedure.

From the patients who underwent a SPW procedure, $151(72.9 \%)$ had gunshot injuries, and $56(27.1 \%)$ had stab wounds. Sixty three (30.4\%) had a single injury, whereas $144(69.6 \%)$ had multiple penetrating wounds. In regard to the physiologic condition at the hospital admittance, 143 patients $(69.1 \%)$ had systolic blood pressure (SBP) above or equal to $90 \mathrm{mmHg}$, and were considered hemodynamic stable and 64 (30.9\%) were considered to have hemodynamic instability, with SBP less then $90 \mathrm{mmHg}$, with good response to fluid replacement. Five $(2.4 \%)$ patients were submitted to a relief pericardic puncture, and $1(20 \%)$ of these patients had a false-positive SPW. Only 4 patients had performed ECHO prior to the procedure, and $2(50 \%)$ had a confirmed positive result, one $(25 \%)$ had a confirmed negative result and the other one $(25 \%)$ had a negative $\mathrm{ECHO}$ with positive SPW.

From the patients who underwent a TDP procedure, the wound was caused by gunshot in $26(68.4 \%)$ while 12 $(31.6 \%)$ were victims of stab wound. Eleven patients $(29 \%)$ had a single injury in the abdominal and/or thoracic wall, and $27(71 \%)$ had multiple wounds. It was found that 30 patients $(78.9 \%)$ had SBP $>90 \mathrm{mmHg}$, and $8(21.1 \%)$ had SBP less then $90 \mathrm{mmHg}$, also with good response to fluid replacement. None of these patients were submitted to pericardic puncture before the TDP. Two (5.3\%) patients underwent a previous ECHO, with a confirmed negative result. Characteristics of both groups are compared on Table 1.

TABLE 1 - Characteristics of the SPW and TDP techniques.

\begin{tabular}{lllc}
\hline & & SPW (\%) & TDP(\%) \\
\cline { 3 - 4 } MECHANISM OF TRAUMA & Gunshot & 72.9 & 68.4 \\
& Stab wound & 27.1 & 31.6 \\
\multirow{2}{*}{ NUMBER OF WOUNDS } & Single & 30.4 & 29.0 \\
& Multiple & 69.6 & 71.0 \\
& Stable & 69.1 & 78.9 \\
& Instable & 30.9 & 21.1 \\
\hline
\end{tabular}


Twelve (31.6\%) patients who underwent the TDP had a hollow viscera perforation, while $53(25.6 \%)$ of those who underwent the SPW procedure had the same injury.

The most common injured organs and structures noted in the SPW procedure were liver (32.8\%), diaphragm (20.4\%), stomach (16.9\%) and colon (14\%), whereas in the TDP procedure, the most common injuries were diaphragm (42.1\%), liver (36.8\%), stomach (26.3\%) and colon (18.4\%).

The TDP patients had an ISS index ranging from 2 to 50 , with 18 of average, while the SPW patients had ISS index ranging from 1 to 57 with an average of 19.9. The severity of the anatomic injuries was similar in the two groups.

Results of the PW procedure were true-positive in 44 patients (18\%) and true-negative in 192 patients (78.4\%). All 44 patients with true positive and eight with falsepositive underwent immediate median sternotomies (59.6\%) or thoracotomies $(40.4 \%)$. Comparing the two groups, there was no statistical difference between the SPW and TDP techniques (Table 2).

TABLE 2 - Comparison between techniques.

\begin{tabular}{llcl}
\hline & SPW (\%) & TDP(\%) & pVALUE \\
Sensitivity & 97.5 & 100.0 & NS \\
Specificity & 95.8 & 97.0 & NS \\
Positive predictive value & 84.8 & 83.3 & NS \\
Negative predictive value & 99.4 & 100.0 & NS \\
Accuracy & 96.1 & 97.4 & NS \\
Legend: NS = no statistically significant & & & \\
\hline
\end{tabular}

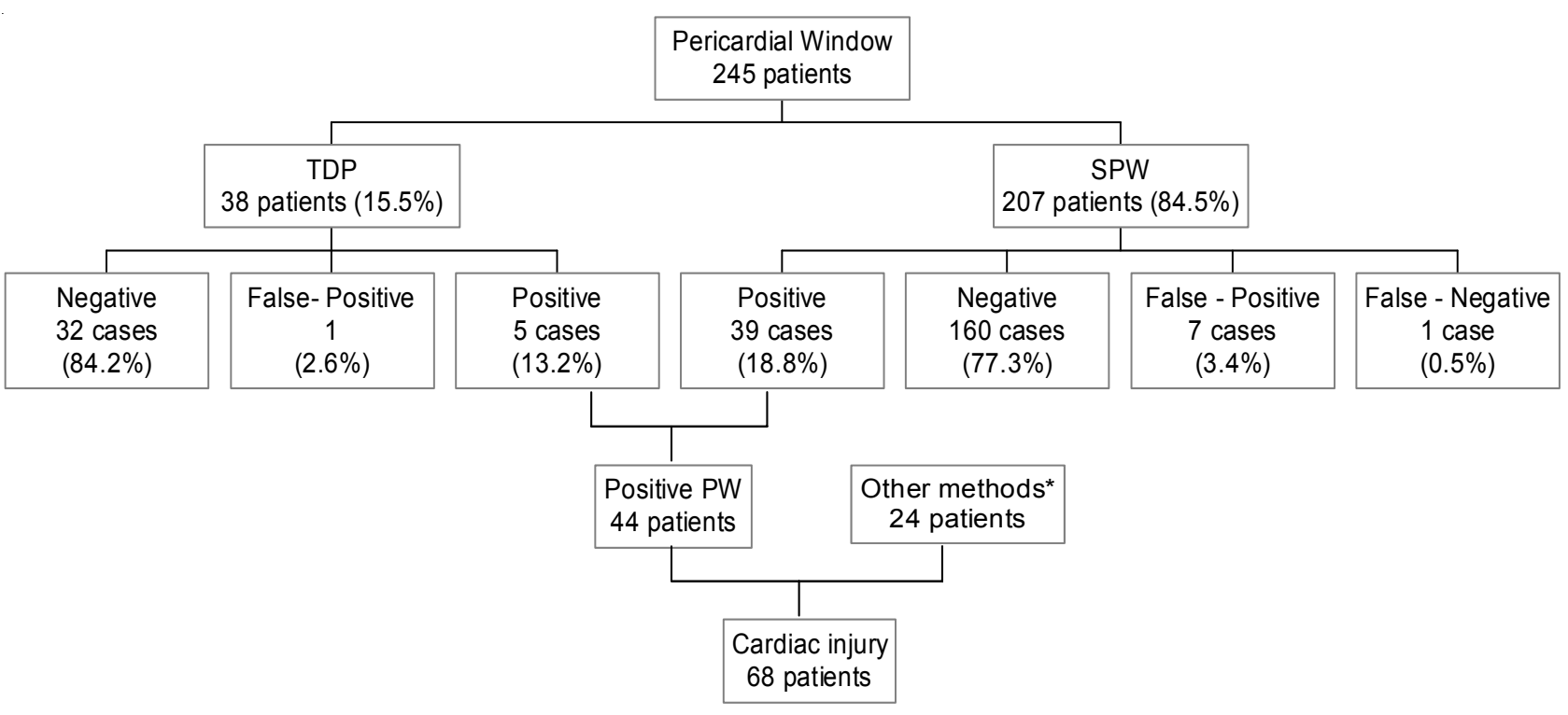

* Other diagnostic methods: thoracotomy, thoracoscopy, ECHO.

FIGURE 2 - Algorithm representing the results for patients in this study.

However, the TDP procedure had showed one $(2.6 \%)$ false-positive and no false-negative results. All eight patients with unexpected results had gunshot wounds and are listed on Table 3. 
TABLE 3 - SPW and TDP false positive results.

\begin{tabular}{lllll}
\hline TECHNIQUE & SBP & ISS & ASSOCIATED INJURIES & INCISION \\
SPW & 110 & 18 & pancreas & Sternotomy \\
SPW & 60 & 38 & liver, small intestine & Sternotomy \\
SPW & 140 & 19 & stomach, colon, liver & Sternotomy \\
SPW & 120 & 14 & small intestine & Thoracotomy \\
SPW & 110 & 27 & liver, diaphragm & Thoracotomy \\
SPW & 80 & 41 & diaphragm, kidney & Thoracotomy \\
SPW & 80 & 10 & none & Thoracotomy \\
TDP & 120 & 34 & liver & Thoracotomy \\
\hline
\end{tabular}

The false negative result was on a stable patient with thoracoabdominal stab wound who was submitted to SPW procedure, with no sign of cardiac injury. However, at laparotomy, the lesion was visualized next to the heart, and it was found to be a grade I cardiac injury, with no need of surgical intervention.

It was found that $199(81.2 \%)$ patients submitted to either of the two PW procedure had no cardiac injury, 6 $(2.4 \%)$ had a grade I, nine $(3.7 \%)$ had a grade II, three $(1.2 \%)$ had a grade III, $18(7.3 \%)$ had a grade IV and $10(4.1 \%)$ had a grade $\mathrm{V}$ cardiac injury.

The morbidity was $44.4 \%$ (92 cases) in the SPW technique, and $39.5 \%$ (15 cases) in the TDP technique. The most common complication, in both techniques, was of pulmonary nature. There was only one $(0.4 \%)$ complication due to the procedure and it occurred in an obese patient with multiple gunshot injuries, with peritoneal cavity contamination and negative TDP. Although the concern about surgery contamination, this patient had pericarditis, and therefore was re-operated to drain the pericardic sac. He stayed in the hospital for 28 days.

Nineteen patients $(9.2 \%)$ died in the SPW group and $3(7.9 \%)$ in the TDP; however, none of these deaths were directly related to the procedure. From all 68 patients with cardiac penetrating trauma treated by our service over the last 11 years, the mortality rate was $16.2 \%$ (11 cases).

\section{Discussion}

Autopsy studies have shown that only a few victims of penetrating heart wounds reach the hospital alive. In Campinas, a one-million-inhabitant city in the State of São Paulo, in Brazil, there were 1,976 deaths by external causes in the years 2000 and 2001, being the majority (65.5\%) after penetrating trauma ${ }^{2}$. Heart injuries were identified in 359 cases autopsied in the Campinas Medical Legal Institute during this period, and only $5.6 \%$ of the victims who died received effective medical care such as thoracotomy. Therefore, the patients described in the present study represent a minority of patients with penetrating injuries to the heart, when there was enough time to use a diagnostic method.

The location of the wound in patients with torso injuries, regardless of signs or symptoms of cardiac tamponade, sustain an aggressive investigation ${ }^{4,5,7,14}$. We define the risk area as a rectangle bounded laterally by the midclavicular line, superiorly by the clavicles, and inferiorly by the costal margin ${ }^{7,9,18,20}$. The stable patients with occult cardiac injury may be at death risk from cardiac tamponade, so it is important not to delay the diagnosis and treatment of these injuries.

We prefer to begin our evaluation of the stable patients with penetrating wound in the proximity to the heart with a noninvasive method. In our hospital, the pericardial ultrasound examinations are performed and interpreted by experienced cardiologists. The trauma team has to call this specialist, sometimes with delays related to the arrival of the cardiologist sonographer and the time of the examination. In the literature, ECHO has clearly emerged as a good technique for penetrating cardiac injury diagnostic, with high sensitivity and specificity, ranged from 97 to $100 \%{ }^{9-13}$.

Ultrasound is an accurate and rapid method to detect hemopericardium, and could be performed and interpreted by trained surgeons ${ }^{12}$. Potential deficiencies of $\mathrm{ECHO}$ are the inexperience of investigators, low machine resolution, presence of severe chest-wall injury, subcutaneous emphysema, obesity, associated pneumothorax or hemothorax.

To rule out cardiac and diaphragmatic injuries in thoracoabdominal trauma, the videothoracoscopy has been recently reported as a useful approach ${ }^{18,19}$. Morales et al. ${ }^{19}$ described a series with 108 patients submitted to thoracoscopic pericardial window, with hemopericardium in 33 patients $(30.6 \%)$. The procedure showed a $100 \%$ sensitivity, $96 \%$ specificity, and $97 \%$ accuracy. The authors concluded that it was a precise, rapid and safe method for the diagnosis of heart injury in stable patients ${ }^{19}$. At UNICAMP, we have used this method in some cases.

PW still remains the gold standard of all diagnostic procedures for cardiac injuries in a developing country like ours. However, it is an invasive procedure and requires a general anesthesia. The original PW technique was described by Larrey at the eighteenth century, and Arom et al. ${ }^{15}$, in 1977, described the SPW as a safe and effective procedure in the diagnosis of pericardial tamponade ${ }^{15}$. In 1982, Garrison et al. ${ }^{16}$ described the TDP to be performed during the conduct of an exploratory laparotomy in the patient with combined thoracoabdominal trauma. Recently, the experience with TDP in our service was published in the Brazilian literature ${ }^{17}$.

$\mathrm{PW}$ is an accurate means for diagnosing cardiac injury. Grewal et al. ${ }^{6}$ described in 1995 the biggest casuistic of SPW in the literature, with 122 patients (Table 4). 
TABLE 4 - Comparison between our results and the literature.

\begin{tabular}{|c|c|c|c|c|}
\hline AUTHOR & $\begin{array}{c}\text { TOTAL } \\
\text { OFCASES }\end{array}$ & $\begin{array}{l}\text { TECHNIQUE } \\
\text { SPW / TDP }\end{array}$ & $\begin{array}{l}\text { TRUE-POSITIVE } \\
\text { PW }\end{array}$ & $\begin{array}{l}\text { FALSE-POSITIVE } \\
\text { PW }\end{array}$ \\
\hline Arom et al., $1977^{15}$ & 50 & $50 / 0$ & $16(92 \%)$ & 0 \\
\hline Garrison et al., $1982^{16}$ & 60 & $0 / 60$ & $17(28.3 \%)$ & $2(3.3 \%)$ \\
\hline Miller et al., $1987^{4}$ & 104 & $88 / 16$ & $19(18.3 \%)$ & $1(1 \%)$ \\
\hline Brewster et al., $1988^{5}$ & 108 & $69 / 39$ & $30(27.8 \%)$ & $2(1.9 \%)$ \\
\hline Duncan et al., $1989^{7}$ & 51 & $51 / 0$ & $12(23.5 \%)$ & 0 \\
\hline Mayor-Davies et al., $1990^{14}$ & 10 & $10 / 0$ & $6(60 \%)$ & 0 \\
\hline Andrade-Alegre et al., $1994^{24}$ & 76 & $76 / 0$ & $16(21 \%)$ & 0 \\
\hline Grewal et al., $1995^{6}$ & 122 & $122 / 0$ & $26(21.3 \%)$ & $0^{*}$ \\
\hline Present study, 2007 & 245 & $207 / 38$ & $44(18 \%)$ & $8(3.3 \%)$ \\
\hline
\end{tabular}

Legend: * = two false-positive PW in whom there were isolated pericardium lacerations.

These authors found a $92 \%$ sensitivity and $100 \%$ specificity using this method. In the present study, the sensitivity was $97.5 \%$ in SPW and $100 \%$ using TDP, while specificity was $95.8 \%$ in SPW and $97 \%$ in TDP. Our results were damaged by the high incidence $(3.3 \%)$ of false-positive results.

Previous studies showed that false-positive results are possible due to inadvertent technique ${ }^{4-6,16}$. Garrison et al. ${ }^{16}$ had two patients with TDP positive with pericardial but no myocardial injury. The same was observed by Grewal et al. ${ }^{6}$, who have classified two "false-positive" windows, in which there were isolated pericardium lacerations, resulting in bloody pericardial fluid and consequent sternotomy. Miller et al. ${ }^{4}$ described one false-positive result in which blood was present in the pericardic sac, but no heart injury was detected at operation. Brewester et al. ${ }^{5}$ had two patients with positive SPW and no cardiac injury. As illustrated on Table 3, we observed false-positive results in eight patients (3.3\%). All patients were victims of multiple gunshot wounds, with many associated injuries and an ISS average of 25.1. Since the techniques provide direct visualization of the pericardial sac, it is consistent in its accuracy. However, in some patients the pericardium is hardly visualized, and the pericardium incision to view the heart base may produce some bleeding, which can be wrongly detected by the surgeon, who inadvertently may indicate a sternotomy or thoracotomy.

One patient was submitted to a relief pericardiocentesis that has resulted in a false-positive PW. Because of its unreliable results and of the possibility of serious complications, such as coronary artery or cardiac laceration, diagnostic pericardiocentesis is currently not used in our service.

A policy of mandatory use of a catheter through the previously made aperture in the pericardium to irrigate the pericardic sac with saline solution has reduced the incidence of false-positive results since 2000, avoiding unnecessary thoracotomies.

This study included a patient with initial negative SPW; however, when he was submitted to exploratory laparotomy, a pericardic injury was identified. This laceration was washed with saline solution and clear fluid has returned being considered a grade I cardiac injury, avoiding thoracotomy.

Conservatory treatment of cardiac injury in stable patients, although described by Blalock et al. ${ }^{3}$, is an exceptional behavior, and most authors still recommend early surgery. Recently, Navsaria et al. ${ }^{23}$, in a prospective study, have observed that ten $(71.4 \%)$ of 14 stable patients with positive PW had minor cardiac injury (grade I to III) identified at sternotomy, and this procedure could have been avoided. A group of seven patients, mainly victims of stab wounds $(85.7 \%)$, has been submitted to PW procedure, usually 48 hours after the trauma, followed by drainage and observing. These patients stayed in the hospital for 4.7 days, and had a good evolution ${ }^{23}$. In the present study, only one patient who presented a grade I cardiac injury was not treated by thoracotomy. Although this surgical procedure could be interpreted as non-therapeutic, the tamponading was prevented by the surgical correction.

In the present casuistic, most of the patients (70\%) had multiple wounds and the majority was located in the thoracoabdominal area. Associated abdominal injuries were identified in 20 patients $(52.6 \%)$ submitted to TDP procedure and in 59 patients $(33.5 \%)$ submitted to SPW procedure. In patients with combined risk of cardiac and diaphragmatic injury, the surgical investigation is mandatory in our service, because we do not believe in an accurate noninvasive method in the diagnosis of diaphragm perforation, and we believe that all diaphragmatic injuries should be sutured. When videothoracoscopy or videolaparoscopy are not available, as in the present study, exploratory laparotomy is indicated, resulting in high incidence of non-therapeutic procedure (SPW had 33.5\% and TDP had 47.4\%). The hollow viscera perforation is a situation that requires special attention, mainly in the TDP method, due to possible infectious complications. There were 53 patients $(25.6 \%)$ with hollow viscera perforation in SPW and $12(31.6 \%)$ in TDP method. This finding does not counter-indicate none of the procedures ${ }^{4,5,16}$. However, in the present study, one patient with stomach and colon injuries, besides the concern of contamination during the surgical procedure, had pericarditis. He had to be re-operated, and had to stay in the hospital for 28 days. Our service does not have the 
intention to perform TDP when there is great abdominal contamination with excrements, and in this case, the surgeon has wrongly opted for this method. In these cases we perform SPW procedure, paying special attention to avoid contamination.

The PW procedure allows quick diagnosis of cardiac injury in patients with a wound in the proximity of the heart. Both techniques present equally great results, with high sensitivity and specificity. The TDP can be successfully done when the patient has thoracoabdominal wounds, and is submitted to a laparotomy. Both surgical techniques must be carefully done, especially in cases of multiple wounds, in order to avoid false positive results. The TDP must be even more carefully done in the presence of contamination of the peritoneal cavity, thus avoiding infectious complications in the heart.

\section{Conclusions}

Both techniques presented an equally great result, with high sensitivity and specificity. Both surgical techniques must be carefully done to avoid false positive results.

\section{References}

1. Asensio JA, Soto SN, Forno W, Roldan G, Petrone P, Salim A, Rowe V, Demetriades D. Penetrating cardiac injuries: a complex challenge. Injury. 2001;32:533-43.

2. Fraga GP, Heinzl LR, Longhi BS, Silva DC, Fernandes Neto FA, Mantovani M. Cardiac trauma: autopsy findings. Rev Col Bras Cir. 2004;31:38690.

3. Blalock A, Ravitch MM. A consideration of the nonoperative treatment of cardiac tamponade resulting from wounds of the heart. Surgery. 1943;14:157-62.

4. Miller FB, Bond SJ, Shumate CR, Polk HC, Richardson JD. Diagnostic Pericardial Window. Arch Surg. 1987;122:605-9.

5. Brewster SA, Thirlby RC, Snyder III WH. Subxiphoid Pericardial Window and Penetrating Cardiac Trauma. Arch Surg. 1988;123:937-41.

6. Grewal H, Ivatury RR, Divakar M, Simon RJ, Rohman M. Evaluation of Subxiphoid pericardial window used in the detection of occult cardiac injury. Injury. 1995;26:305-10.

7. Duncan AO, Scalea TM, Sclafani SJA, Phillips T, Bryan D, Atweh NA, Vieux EE. Evaluation of Occult Cardiac Injuries Using Subxiphoid Pericardial Window. J Trauma. 1989;29:955-60.

8. Prado PA, Saad Júnior R, Rasslan S. Pericardical Window in the diagnosis of cardiac injuries. Rev Col Bras Cir. 1995;22:307-12.

9. Nagy KK, Lohmann C, Kim DO, Barrett J. Role of echocardiography in the diagnosis of occult penetrating cardiac injury. J Trauma. 1995;38:85962.

10. Jimenez E, Martin M, Krukenkamp I, Barrett J. Subxiphoid pericardiotomy versus echocardiography: a prospective evaluation of the diagnosis of occult penetrating cardiac injury. Surgery. 1990;108:676-80.

11. Freshman SP, Wisner DH, Weber CJ. 2-D echocardiography: emergent use in the evaluation of penetrating precordial trauma. J Trauma. 1991;31:902-6.

12. Rozycki GS, Feliciano DV, Ochsner MG, Knudson MM, Hoyt DB, Davis F, Hammerman D, Figueredo V, Harviel D, Han DC, Schmidt JA. The role of ultrasound in patients with possible penetrating cardiac wounds: a prospective multicenter study. J Trauma. 1999;46: 543-52.

13. Tayal VS, Batty MA, Marx JA, Tomaszewski CA, Thomason MH. FAST (focused assessment with sonography in trauma) accurate for cardiac and intraperitoneal injury in penetrating anterior chest trauma. J Ultrasound Med. 2004;23:467-72.

14. Mayor-Davies A, Britz RS. Subxiphoid Pericardial Windows - Helpful in Selected Cases. J Trauma. 1990;30:1399-401.

15. Arom KV, Richardson JD, Webb G, Grover FL, Trinkle K. Subxiphoid Pericardial Window in Patients with Suspected Traumatic Pericardial Tamponade. Ann Thorac Surg. 1977;23:545-9.

16. Garrison RN, Richardson JD, Fry DE. Diagnostic Transdiaphragmatic pericardiotomy in thoracoabdominal trauma. J Trauma. 1982;22:1479.

17. Mantovani M, Espinola JP, Fraga GP. Transdiaphragmatic pericardial window in the diagnosis of cardiac injury. Rev Col Bras Cir. 2006;33:29-34.

18. Pons F, Lang-Lazdunski L, Kerangal X, Chapuis O, Bonnet PM, Jancovici R. The role of videothoracoscopy in management of precordial thoracic penetrating injuries. Eur J Cardiothorac Surg. 2002;22:7-12.

19. Morales CH, Salinas CM, Henao CA, Patiño PA, Muñoz CM. Thoracoscopic pericardial window and penetrating cardiac trauma. J Trauma. 1997;42:273-5.

20. American College of Surgeons Committee on Trauma: Advanced Trauma Life Support Course Manual. American College of Surgeons, 2002.

21. Baker SP, O'Neill B, Haddon Jr W, Long WB. The Injury Severity Score: a method for describing patients with multiple injuries and evaluating emergency care. J Trauma. 1974; 14:187-96.

22. Moore EE, Malangoni ME, Cogbill TH, Shackford SR, Champion HR, Jurkovich GJ, McAninch JW, Trafton PG. Organ Injury Scaling IV: Thoracic 
vascular, lung, cardiac, and diaphragm. J Trauma. 1994;36:299-300.

23. Navsaria PH, Nicol AJ. Haemopericardium in stable patients after penetrating injury: is subxiphoid pericardial window and drainage enough? A prospective study. Injury. 2005;36:745-50.

24. Andrade-Alegre R, Mon L. Subxiphoid pericardial window in the diagnosis of penetrating cardiac trauma. Ann Thorac Surg. 1994;58:1139-41

\section{Correspondence:}

Gustavo Pereira Fraga

Av. Cel. Silva Telles, 211 apt. 3

13024-000 Campinas - SPBrasil

Fone: (55-19) 3294-6348

fragagp@,uol.com.br
Conflict of interest: none Financial source: Foundation of Support to Research of the State of São Paulo (FAPESP - 05/50641-6)

Received: September 11, 2007

Review: November 12, 2007

Accepted: December 10, 2007

\section{How to cite this article}

Fraga GP, Espínola JP, Mantovani M. Pericardial window used in the diagnosis of cardiac injury. Acta Cir Bras. [serial on the Internet] 2008 Mar-Apr;23(2). Available from URL:URL:http://www.scielo.br/acb 